\title{
MODERNIDAD, TOLERANCIA Y MIGRACIÓN: CONSECUENCIAS PARA LA EDUCACIÓN EN CHILE*
}

\author{
ENRIQue Muñoz PÉrez ${ }^{1}$ \\ Jorge Alarcón Leiva ${ }^{2}$ \\ Susan Sanhueza Henríquez ${ }^{3}$
}

\begin{abstract}
RESUMEN: El artículo propone volver a pensar las categorías de "modernidad", "tolerancia" y "migración", estableciendo su alcance, en particular, para la educación en Chile. La tesis que pone en discusión es que la migración supone la necesidad de modificar la relación entre modernidad y tolerancia, lo que debe ser atendido por las políticas públicas en educación, que en el caso chileno se muestran precarias e insuficientes.
\end{abstract}

Palabras clave: Tolerancia. Migración. Educación. Multiculturalidad.

\section{MODERNITY, TOLERANCE AND MIGRATION: CONSEQUENCES FOR THE EDUCATION IN CHILE}

\begin{abstract}
The article proposes to think again the categories of "modernity", "tolerance" and "migration", establishing its scope, in particular, for to education in Chile. The thesis that puts it is discussion is that the migration supposes the need to modify the relation between modernity and tolerance, which must be taken care of by the public policies in education, that they are precarious and insufficient in the Chilean case.
\end{abstract}

Keywords: Tolerance. Migration. Education. Multiculturality.

\footnotetext{
*Este artículo es producto del proyecto de investigación CONICYT PIA SOC 1401, denominado "Inmigrantes en el sistema educacional de Chile. Representaciones de género, lengua, territorialidad y exclusión social” (2015-2018) financiado por CONICYT - Chile (Consejo Nacional de Ciencia y Tecnología).

${ }^{1}$ Universidad Católica del Maule, Facultad de Ciencias Religiosas y Filosóficas, Departamento de Filosofía - Talca, Chile. E-mails: enmunoz@ucm.cl, envlamupe@yahoo.com

${ }^{2}$ Universidad de Talca, Instituto de Investigación y Desarrollo Educacional - Talca, Chile. E-mail: joalaracon@utalca.cl

${ }^{3}$ Universidad Católica del Maule, Facultad de Ciencias de la Educación, Departamento de Fundamentos de la Educación - Talca, Chile. E-mail: ssanhueza@ucm.cl

DOI: 10.1590/ES0101-73302018178659
} 


\section{MODERNITÉ, TOLERANCE ET MIGRATION: CONSÉQUENCES POUR L'EDUCATION AU CHILI}

RESUMÉ: L'article propose de repenser les catégories de la "modernité », la " tolérance " et la « migration ", en établissant son champ d'application, en particulier l'éducation au Chili. La thèse est que la migration implique la nécessité de changer la relation entre la modernité et la tolérance, qui doit être abordée par des politiques publiques en matière d'éducation, qui dans le cas du Chili est précaire et insuffisante.

Mots-clés: Tolérance. Migration. Éducation. Multiculturalisme.

\section{Introducción}

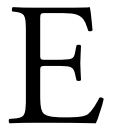

ste artículo comenzó a escribirse unos meses después de los atentados en Bruselas (Bélgica) y de los cruentos ataques llevados a cabo en París (Francia) y en Múnich (Alemania), por parte de extremistas fundamentalistas islámicos que, en todos los casos, costaron la vida a personas inocentes. Hechos condenables, donde los haya, que se enmarcan en unos años marcados por los efectos de la migración, dados los flujos de personas provenientes desde África y Medio Oriente, que han convergido en Europa; pero especialmente por el tono del debate instalado en el mundo entero acerca de la forma en que debe abordarse la que cabe llamar ya la "cuestión migratoria".

En este sentido, el solo hecho que la opinión pública vincule los atentados con la migración - como aconteció en los casos de Bruselas y París —, debiera suscitar una reflexión sobre los límites de la tolerancia en las democracias de occidente, habida cuenta de las opiniones alarmistas que suelen aparecer al respecto en los medios de comunicación y, por cierto, del rol que le cabe a la educación en esta problemática.

De esta manera, es la cuestión general de la migración la que se pretende abordar en este trabajo, desde una perspectiva que acopie materiales para una consideración relativa a los grados de (in)tolerancia con que se comportan ciudadanos de distintas naciones del mundo y que muestran el estado de las instituciones políticas en muchas partes del orbe. En este tenor, lo que interesa discutir es la relación entre las sociedades mayoritarias o dominantes con los grupos de migrantes. Por eso el título del artículo sugiere un vínculo entre "modernidad", "tolerancia" y "migración", en la medida que se asume que la cuestión central del trabajo exige volver a atender tales nociones $y$, particularmente, establecer sus alcances e implicaciones educativas.

Desde que alcanzara el estatus filosófico que le brindara Hegel, la "modernidad" ha sido problematizada en múltiples ocasiones en las últimas décadas del siglo XX y las primeras del siglo XXI. En el marco de tales discusiones, el pro- 
blema de la "tolerancia" se ha vuelto a plantear en términos de cómo desarrollar, en las sociedades así llamadas "modernas", las relaciones entre grupos mayoritarios y ciertos grupos minoritarios - étnicos, religiosos, culturales, sexuales, etc. En dos palabras, la sociedad moderna — fundada bajo los supuestos políticos universalistas de libertad, igualdad y fraternidad - , ha debido reconocer la existencia de grupos olvidados, ignorados, discriminados o perseguidos en su seno, haciendo evidente su propio déficit. De forma que la migración, como quiera que se la mire, trae aparejada la necesidad de revisitar algunos de los tópicos modernos.

Por otro lado, el locus clásico de la modernidad desde Locke, esto es, la "tolerancia", ha mutado para adoptar la forma de la dialéctica inclusión-exclusión, en cuyo contexto la migración se muestra como fenómeno crítico. Es este fenómeno el que justifica volver a plantear la pregunta de si jes el fenómeno de la migración una renovación del problema moderno de la tolerancia, bajo el rótulo de la dialéctica inclusión-exclusión, o exige un planteamiento completamente inédito?, ¿Qué consecuencias tiene ello para la educación en Chile?

La tesis que se defiende es, entonces, que la migración supone la necesidad de modificar el modo de concebir la relación entre modernidad y tolerancia. El trabajo se propone, en este sentido, identificar cuáles son las implicaciones de tal cambio. Dicho de otra forma, si la filosofía política moderna se abocó a establecer mecanismos de entendimiento mutuo, por ejemplo, entre grupos religiosos diversos, y propuso como medio de solución de los conflictos la práctica de la "tolerancia"; ese planteamiento, se torna hoy cuando menos insuficiente, porque el fenómeno migratorio pone en tensión los modernos modelos políticos, situándonos en un horizonte moral distinto, al poner en tensión las instituciones sociales y sus capacidades y formas características de proveer servicios que cubran derechos. Un caso, desde luego que no el único, es el de la educación.

Por consiguiente, el artículo se divide en una primera parte relativa a los conceptos de modernidad, tolerancia y migración, y, en una segunda parte, se aboca a una consideración de las consecuencias para la educación, partiendo de algunos elementos de la experiencia chilena.

\section{Nosotros y los Otros: migrantes en la narrativa moderna}

Una de las primeras cuestiones que debe ser clarificada, es la extensión de los conceptos "modernidad", "tolerancia" y "migración". La tradicional motivación explicativa referida a dilucidar el significado de "moderno/a", en referencia al modo de concebir el pasado a partir del presente, según la vieja suposición proveniente de la querella entre antiguos y modernos, ha sido desplazada por las tensiones actualmente existentes entre estado y mercado. Dicho de otro modo, mientras que convencionalmente la explicación acerca de lo "moderno" conllevaba un abstracto gesto de neutralización del peso de la tradición y, por conse- 
cuencia, de la historia, hoy parece más bien estar vinculada a las formas concretas de organización de la vida y sus consecuencias para la vida individual y colectiva.

Tampoco es claro el alcance del término "migración", que pareciera reducirse en la actualidad únicamente a personas pobres y vulnerables que van desde sus lugares de origen, a otros lugares económicamente más desarrollados para mejorar su calidad de vida material. En esa línea, un profesional estadounidense o europeo que trabaje en Chile, no sería calificado inmediatamente de "migrante", supuesta su mejor condición comparada para aspirar a una posición laboral de privilegio. En una importante medida, se quiere sugerir, que la migración se sobreentiende como desplazamiento humano causado por necesidades de orden económico, dejando en segundo plano las cuestiones sociales, políticas y culturales que también implica. Que, de hecho, implica prioritariamente.

Algo similar ocurre, finalmente, con el concepto de "tolerancia", dado que pareciera tener sentido, como dijimos, solo para individuos que pertenecen a una misma comunidad, no para grupos de individuos que constituyen comunidades distintas y que, debido a lo mismo, no son parte de un "nosotros". De hecho, pudiera decirse que concebido en la forma tradicional, el concepto de "tolerancia" dice poco y nada acerca de la migración, tal como aparece hoy en los acontecimientos que se le relacionan. O quizás al revés: el migrante es un personaje nuevo en la narrativa moderna y, en consecuencia, pocas de sus concepciones asociadas se le aplican con sentido. En parte importante, la cercanía física del migrante, su peculiar pertenencia a "mi comunidad", mediante su "acto de presencia", hace que no sea considerado "extraño" sino alguien que es parte de nosotros, sin serlo.

Procuraremos, a continuación, mostrar un "estado del arte" de estos conceptos con el objeto de establecer algunas delimitaciones básicas que permitan presentar las consecuencias de esta discusión para la educación, en un momento histórico que la experiencia educativa es quizás la expresión social fundamental de las dificultades suscitadas por el movimiento migratorio.

\section{Concepto de modernidad: del estado al mercado y del ciudadano al consumidor}

Convendrá reconocer que cualquier referencia a la noción "moderno", se presenta cargada de un conjunto tan amplio de dificultades que es complejo determinar siquiera por dónde comenzar el examen. En efecto, no solo la acostumbrada densidad semántica acompaña a la noción, sino que también un amplio espectro de oscilaciones le confiere también una característica sensibilidad teórica. El concepto es, en suma, esquivo ${ }^{1}$.

Una manera de abordarlo, entre varias, como se ha dicho, consiste en intentar precisar su alcance "gramatical", vale decir, delimitar formalmente sus 
contornos, considerando al concepto sin referencia a sus múltiples variaciones, contrastes y variopintos contenidos contextuales. Una tal referencia al concepto permite entenderlo en un sentido semejante al que Hegel le atribuyó en relación con la experiencia del tiempo o, mejor, con la manera en que dicha experiencia es individual y constituye una forma de relación con el presente temporal y, en consecuencia, con el pasado y el futuro. "Moderna”, en este sentido, sería una forma de referirse a la experiencia subjetiva, que transforma el tiempo en "continuo presente" y que, si cabe seguir hablando en este sentido enigmático, se experimenta como síntesis, como sinopsis superadora de la tensión entre pasado y futuro: presente puro que se consuma en su ser puro presente (HABERMAS, 1993, p. 35); una inmanencia que es, justo, lo que brinda a la modernidad un halo terrenal, secularizado, motivo central del así llamado "pensamiento moderno".

"Moderna" resulta así la perspectiva que da cuenta del ropaje exterior que caracteriza a la sociedad europea desde el Siglo XVIII y que se vincula "internamente" con el racionalismo propio de las sociedades europeas, que permitiera tanto el desencantamiento de las imágenes religiosas del mundo cuanto la evolución de las sociedades. Justamente este es el momento en que Habermas estima que la modernidad alcanzó estatuto filosófico (HABERMAS, 1993, p. 8). El momento en que la modernidad se eleva a tema filosófico es, para él, aquel en que puede decirse que alcanza una cierta forma de conciencia del tiempo y en que se persigue alguna forma de autocercioramiento (HABERMAS, 1993, p. 11). Conciencia del tiempo y autocerteza son, digamos, los rasgos que definen la moderna forma de experimentar la vida.

Tener esta conciencia y disponer de tal forma de autocercioramiento, se desligaría con el tiempo, sin embargo, de la transformación social misma. Mientras que, en efecto, la sociedad evolucionó hacia:

Una gavilla de procesos acumulativos y que se refuerzan mutuamente: a la formación de capital y a la movilización de recursos; al desarrollo de las fuerzas productivas y al incremento de la productividad del trabajo; a la implantación de poderes políticos centralizados y al desarrollo de identidades nacionales; a la difusión de los derechos de participación política, de las formas de vida urbana y de la educación formal; a la secularización de valores y normas (HABERMAS, 1993, p. 12).

Es decir, el ideal racional que Weber (1991) describió como relacionado con esta evolución, quedaría o relegado o desvinculado, al modo de un ideario.

Mientras que el ideario pareció muerto, sus consecuencias siguen o pueden seguir un curso independiente: de ahí la idea, también habermasiana, de una modernidad inacabada o la de su sucesión histórica por la postmodernidad, conforme al parecer de otros. Sobre esta base, en consecuencia, se establece la posible desvinculación entre modernidad y modernización, entre el proyecto social 
heredero de los valores ilustrados y el devenir histórico del crecimiento industrial sin regla. Mientras que el primero perseverará en el ideal de bienes universalmente accesibles; el segundo, distribuirá tales bienes en virtud del ingreso. De hecho, la idea misma de progreso, y sus eventuales derivaciones, será concebida como mero florecimientos de la calidad de vida o como el reflejo simple y llano de la distribución promedio del ingreso per cápita. Público y privado, estado y mercado, serán las formas mediante las cuales se hará efectiva la diferencia entre una manera y otra de vivir la vida (ATRIA, 2014).

Adoptada esta diferenciación entre el ideario y las consecuencias, desde los años 50 en adelante pudo distinguirse entre sociedad moderna y procesos de modernización. Estos últimos implican disponer de la infraestructura física requerida para proveerse de los medios que satisfagan las necesidades de la población:

Desde este punto de vista, la modernización social, que seguiría discurriendo autárquicamente, se habría desprendido de la modernidad cultural, al parecer ya obsoleta; esa modernidad social se limitaría a ejecutar las leyes funcionales de la economía y del Estado, de la ciencia y de la técnica, que supuestamente se habrían aunado para constituir un sistema ya no influible (HABERMAS, 1993, p. 13).

"Moderna" es una sociedad en la que no solo hay cosas, sino un tipo particular de objetos que, digamos, funciona gracias a un cierto conjunto de fuerzas procedentes de un tipo particular de energía - la fuerza del trabajo humano, del petróleo, de la electricidad, básicamente. Objetos y fuerzas que configuran una experiencia, como antes se ha dicho ya: una forma de percibir individualmente el medio exterior y una forma de experimentarlo colectivamente. Las cosas, el sistema de los objetos, el moderno acceso a los bienes físicos, se transforma en estos casos en experiencia, en significado subjetivo, en potencia imaginativa de nuevos eventos y oportunidades creadas por la relación, la interconexión, la permanente red que se desborda en lo global. La imagen de globo terráqueo que llevamos con nosotros y que se encarna en las formas del vestir y del comer, del creer y del poder, propias y ajenas, todas las cuales conviven allá lejos y aquí cerca, mediante la transición que también se experimenta como paso de la ciudadanía al consumo; de la modernidad cultural a la modernización social, de que se habla a partir de Weber (GARCÍA-CANCLINI, 1995, p. 15-37). Pero que, sobre todo, adopta la forma del temor a las penetrantes miradas de aquellos a quienes encontramos en las calles, a la mirada tosca que muestra que el vecino, que el prójimo, ya no es próximo, que se trata ahora de habitantes que proliferan anónimos por la urbe y cuyo advenimiento se intuye como riesgo.

Eso es también moderno. No solo las cosas que pueblan nuestras vidas, sino que también las ideas, los pensamientos y creencias, los deseos y las frustraciones, la voluntad de ser. Entonces, moderna es una sociedad donde las personas 
gozan de ciertos bienes y también donde esperan, creen, desean, aman, sienten, imaginan, piensan. Personas que también disfrutan, digamos, de una vida interior que es distinta de aquella cuyo mapa se describe señalando objetos exteriores, cuya materialidad nos resulta ajena y, por ello mismo, incierta, insegura. Así que, por contraste a la certeza de mi propia experiencia, se me presenta lo externo - mi propio cuerpo inclusive, en clave argumentativa cartesiana - como lo que no me pertenece, como aquello de lo que no puedo estar cierto sino por un giro hacia el autocercioramiento. La experiencia moderna del mundo halla su certeza precisamente en la propia experiencia: en el yo.

Moderna es esta forma de experiencia que señalamos cuando usamos el pronombre "Yo", en cuyo caso hacemos algo especial: adoptar una perspectiva reflexiva acerca de nosotros mismos. Está, digámoslo así, indicándose cierta forma de pertenencia a sí mismo, cierta relación de posesión consigo mismo que revela certeza, la única posible. Cierta forma de (auto)propiedad en suma. Esta forma es la "propiedad privada". Vale decir, moderna es también una sociedad en que los individuos reclaman para sí la ostentación del derecho en virtud del cual se sienten asistidos para separar lo suyo de lo de los demás. Lo propio de lo ajeno. En este sentido, la afirmación de un sentido de "pertenencia nacional", derivado del sentido de "unidad nacional", caracteriza la experiencia política moderna y circunscribe la provisión de derechos solo a aquellos que son parte de tal nacionalidad. Por principio, y este es un grave problema, los que no pertenecen a ella quedan excluidos.

Podría decirse, inclusive, que una sociedad es característicamente moderna por la forma en que resuelven la tensión entre público y privado, entre nosotros y yo, entre nuestro y mío. Entre "de todos (nosotros)" y "(solo) mío". Esa tensión es a veces un equilibrio y otras veces un desbalance, pero siempre es fragmento, collage, ensamble. Esto pasa cuando lo público se amplía al punto de suprimir lo individual o, inversamente, cuando lo privado suprime lo público. Es el paso, entre una y otra, del poder total del Estado (lo público) al querer absoluto del consumo (lo privado). Ambos, identificados con el poder absoluto o con el deseo neurótico. Podría decirse que es la diferencia entre el tranquilo pasado que anhelamos - el estatismo de que a veces se habla en política - y el desasosiego de un futuro que se nos muestra como evasión e incertidumbre. Como un deseo que posee su objeto o uno que no puede tener el objeto que lo satisface. En ambos casos, como patología del yo que no encuentra en su pura afirmación la paz, pero que tampoco la haya en la confusión con los otros, por su fugacidad. En una forma característica, Chile es el escenario de esta tensión en educación: mientras se piensa en la competencia, el mercado y la elevación de la calidad como medida de operación eficiente, triunfa el mundo privado y su lógica. Entre tanto, la única, y lamentablemente devaluada, forma de concebir lo público es entendiéndolo como propiedad del Estado, vale decir, como siendo de nadie, sujeto a control ninguno y falto de sentido individual a favor de un vago sentido compartido. Esta es la 
encrucijada en la que se encuentra gran parte del problema de la distribución de los bienes públicos y, en particular, es el rasgo del debate político en Chile acerca de la educación.

En la lógica de la modernidad, de este modo, las migraciones irrumpen a un escenario en que la libertad de elegir, y no la igualdad, es la norma. Es por ello que puede representarse la migración como suscitando cuatro etapas: contacto, competencia, acomodación y asimilación. Estas etapas tienen su base histórica en el incipiente desarrollo industrial del Siglo XIX y este matiz económico origina una creciente complejidad. A partir de esta situación, se acuña la expresión Melting Pot ${ }^{2}$, Crisol de Razas o Licuadora Social, entendiéndose como el proceso gradual en que sociedades homogéneas se convierten en heterogéneas, a través de una combinación intensa entre ellas para dar origen a una sociedad multiétnica. Esta es la cuestión que hoy, aunque lejanamente aún, ha puesto la migración al país. Esta cuestión deriva fundamental, pero no únicamente, del hecho que Chile se ha transformado, por una parte, en un país atractivo para poblaciones de inmigrantes que buscan mejores condiciones de vida y, por otra parte, de que el país se concibe a sí mismo como una nación, en el sentido antes señalado, cuyos bienes deben distribuirse como derechos a los nacionales, pero no a los extranjeros.

Aquí radica un doble dilema: ¿cómo hacer que los derechos alcancen para todos, incluyendo a los no nacionales, en una nación en la que los derechos se conciben propios únicamente de los que pertenecen a la comunidad política nacional, pero a estos de formas también diferenciadas?

Se debe considerar que, en el más amplio contexto de interacción entre individuos, propio de sociedades complejas, la discriminación por parte de la sociedad dominante, es un componente de la experiencia cotidiana de las minorías étnicas. Los inmigrantes padecen discriminación en aspectos tan trascendentales como la educación; pues teniendo una precaria situación económica, la accesibilidad a trabajos bien remunerados es baja y, a la vez, se inicia una cadena de circunstancias de vulnerabilidad que desembocan, en el caso de niños y niñas, en la asistencia a establecimientos educativos de bajo nivel y escasas perspectivas sociales.

\section{Concepto de tolerancia: de la tradición y la innovación}

La cuestión de la tolerancia, desde el punto de vista filosófico, remite, en primer lugar, a la obra de John Locke (1994) Carta sobre la tolerancia, que publicara en el año $1689^{3}$. Si bien el objetivo y el contexto en que se desarrolla dicha Carta son distintos del nuestro, es interesante destacar una de sus recomendaciones finales.

Como se sabe, el objetivo de la Carta sobre la tolerancia de Locke es reflexionar sobre la aceptación mutua de los cristianos de diferentes confesiones 
religiosas. En otras palabras, el texto de Locke (1994) busca ser un aporte para solucionar las tensiones religiosas de su época, proponiendo algunos mecanismos que permitan la sana convivencia entre creyentes de diversas tendencias al interior de una misma confesión, lo que por analogía podría ser extendido a los migrantes. Una de las recomendaciones centrales de Locke es que

cada hombre pueda disfrutar de los mismos derechos que son concedidos a los demás. ¿Es permitido adorar a Dios a la manera romana? Que sea también permitido hacerlo a la manera de Ginebra. ¿Se permite hablar latín en un mercado público? Que se permita a quienes deseen hablarlo también en la iglesia. ¿¿̇s legal para un hombre arrodillarse, levantarse, sentarse, o usar cualquier otra postura en su casa y vestirse de blanco o negro, con vestidos largos y cortos? Que no se considere ilegal comer pan, beber vino o lavarse con agua en la Iglesia (LOCKE, 1994, p. 62).

A partir de este principio, es posible deducir el núcleo central de su planteamiento: que en una sociedad moderna y tolerante, lo que se permite a algunos de sus miembros, se permita a todos. Como decíamos, por extensión, si mayoritariamente los chilenos estudian la lengua espańola en sus colegios, profesan la fe cristiana y celebran el mes de la Patria; que también le sea permitido al migrante haitiano en Chile estudiar la lengua francesa, desarrollar ritos vinculados a la santería y celebrar su aniversario nacional. Estos planteamientos, del todo razonables, propuestos por Locke, desde luego exigen un ajuste a la época.

En la actualidad, la discusión sobre la tolerancia vuelve a aparecer y se hace urgente ante los hechos que describíamos al comienzo, siendo uno de los principales representantes Michael Walzer y su conocido libro Tratado sobre la tolerancia (1998). El contexto de la discusión de Walzer son los Estados Unidos y el hecho, aparentemente obvio, que tenemos que tolerar a nuestros semejantes o que la tolerancia forma parte de nuestra vida en comunidad, o que, como diría Locke (1994), lo que se permita a uno se permita a todos.

Walzer (1998) propone, por consiguiente, un marco teórico espléndido para el análisis de la relación entre migración y tolerancia, puesto que estudia al migrante como "lo" diferente, "lo" otro. La tensión que identifica Walzer es que las sociedades modernas son mayoritariamente conservadoras, puesto que buscan mantener y reproducir sus costumbres, tradiciones, lenguas, religión, educación, etc. Los grupos de migrantes vienen, entonces, a desestabilizar esta inercia y sitúan la experiencia social moderna en el lugar en que confluyen tradición e innovación.

Con todo, Walzer (1998) es consciente que la relación entre los sectores dominantes y los grupos de migrantes, tiene una cierta gradualidad, que aprovechamos de subrayar, porque puede ser muy útil para nuestros análisis posteriores relativos a la educación. Hay, a juicio de Walzer, cinco alternativas positivas - naturalmente los contraejemplos serían la discriminación o la xenofobia — que 
pueden tomar los miembros de los grupos dominantes, en relación de los grupos migrantes. Ellas son:

1. La aceptación resignada para mantener la paz, al estilo en que Locke desarrollara su planteamiento en Carta sobre la tolerancia;

2. La indiferencia positiva, relajada, ante la diferencia que no discrimina, necesariamente, pero que tampoco acoge con entusiasmo;

3. Un cierto estoicismo moral, esto es, el reconocimiento, por principio, que los "otros" tienen derechos, aunque ejerciten esos derechos en formas que nos resulten poco atractivas;

4. Una apertura y legítima curiosidad hacia los otros, que se expresa mediante la voluntad de escuchar y aprender de ellos;

5. Y, en definitiva, "la admisión entusiasta de la diferencia" (WALZER, 1998, p. 19).

Con lo anterior, busca Walzer (1998) mostrar la complejidad del problema y de sus alcances. Dado el objetivo de este artículo, podemos preguntar, en primer lugar, ¿qué aporta Walzer (1998), entonces, para el análisis de la relación entre modernidad, tolerancia y migración? y, en segundo lugar, ¿̨cuál de estas perspectivas puede servir para el sistema educacional chileno? Para responder la primera de estas preguntas, debemos sostener que la idea más provocadora de Walzer (1998), en comparación con Locke (1994), es que la otredad no debe ser simplemente tolerada, sino que deber defendida. "Sin duda, las relaciones personales entre las diversas orientaciones culturales mejorarían si se lograra que la gente avance más allá de aquella mínima tolerancia” (WALZER, 1998, p. 20).

Es interesante subrayar esta idea de "defensa de la otredad", puesto que constituye el núcleo de la concepción walzeriana de tolerancia. Según él, la defensa de la otredad se traduce en aquellos actos concretos en que personas que pertenecen a los grupos mayoritarios de una sociedad, facilitan un espacio para quienes tienen ciertas creencias que ellos no adoptan, para quienes realizan determinadas prácticas que ellos no quieren imitar; son personas que "coexisten con otros que siguen siendo algo diferente a lo que ellos conocen, algo extrańo y ajeno. De todas las personas que sean capaces de hacer eso, diré que poseen la virtud de la tolerancia" (WALZER, 1998, p. 21). El criterio propuesto por Walzer (1998) es muy iluminador, puesto que no exige renunciar a las costumbres, tradiciones o lenguajes propios, sino persigue reconocer y defender lo diferente, lo extraño y lo ajeno a las sociedades dominantes.

Dicho esto, cabe responder ahora la segunda de las interrogantes planteadas más arriba, esto es, ¿`cuál de estas perspectivas puede servir para el sistema educacional chileno? La tesis de Walzer (1998) más relevante a este respecto es 
la siguiente: existe una tensión entre la escuela, como agente reproductor de la nación dominante, y los grupos de migrantes, que buscan mantener su lenguaje, costumbres, tradiciones, etc. La manera de solucionar dicha tensión es mediante una educación multicultural ${ }^{4}$. "Habitualmente se dice con razón que la importancia del multiculturalismo consiste en formar a los nińos en la cultura de los otros, en introducir el pluralismo de la sociedad de inmigrantes en las aulas" (WALZER, 1998, p. 104).

Walzer (1998), en su análisis teórico político, revisa un par de modelos escolares tradicionales como contraejemplos al multiculturalismo: el modelo nacional francés y el modelo neutral norteamericano. Según el primero de estos modelos, la identidad nacional es la que antecede a cualquier identidad.

Este tipo de régimen [...] tiene una necesidad mayor de ciudadanos (en particular si está organizado democráticamente), de hombres y mujeres que sean leales, competentes y que estén comprometidos y familiarizados con el estilo, por así decirlo, de la nación dominante. Las escuelas estatales tratarán de producir ciudadanos de ese tipo. Por ejemplo, en Francia a los árabes se les enseñará a ser leales con el Estado francés, a comprometerse con la política francesa, a ser competentes en las prácticas y en los modos en que se expresa la cultura política francesa y a conseguir una buena formación en historia política francesa y en sus estructuras institucionales. Por lo general, parece que los padres y los hijos árabes aceptan estos objetivos educativos; tal como hemos comentado, solamente tratan de afirmar su compromiso árabe o musulmán en lo que se relaciona con el simbolismo de la vestimenta, y no pretenden cambiar el currículo (WALZER, 1998, p. 102).

Con relación al modelo estadounidense, éste respeta las identidades existentes, reconoce los cambios posteriores que puedan darse, pero se mantiene al margen del debate sobre el multiculturalismo.

En este caso a los niños se les enseña que son ciudadanos individuales de una sociedad tolerante y pluralista, donde lo que se tolera es su propia elección de identidad y pertenencia cultural. En su mayoría, evidentemente, ya están identificados, debido a las «elecciones» hechas por sus padres o, como ocurre en el caso de las identidades raciales, a causa de su localización en un sistema social de diferenciación. Pero en tanto que estadounidenses tienen derecho a hacer elecciones posteriores y se les exige que toleren las identidades existentes y las elecciones posteriores de sus compañeros (WALZER, 1998, p. 103).

A juicio de Walzer (1998), ambos modelos de escuela impiden que franceses o norteamericanos se reconozcan como sociedades compuestas de nacionalidades 
heterogéneas y que admiren su propia diversidad, porque en el fondo no se abren, de modo general, a considerar la perspectiva multicultural. Este punto no deja de cobrar relevancia, a propósito de las consideraciones que hacíamos sobre los ataques terroristas al iniciar este texto. Dicho lo anterior, resta abordar el concepto de migración.

\section{Concepto de migración: de los impactos económicos a las consecuencias en todas direcciones}

El Glosario sobre migraciones de la Organización Internacional sobre Migración (2006), recientemente vinculado a la ONU, la define en términos generales como un

movimiento de población hacia el territorio de otro Estado o dentro del mismo que abarca todo movimiento de personas sea cual fuere su tamaño, su composición o sus causas; incluye migración de refugiados, personas desplazadas, personas desarraigadas, migrantes económicos (OIM, 2006, p. 38).

Se trata, en este primer sentido general, en consecuencia, de un hecho que se relaciona básicamente con el movimiento de personas, no importando las causas ni tampoco si acaso el movimiento tiene su destino dentro del mismo Estado o fuera de él. Es, principal y solamente, movimiento de población.

Las cuestiones interesantes son otras. El documento aludido señala que tiene sentido hablar de migración "asistida", "clandestina", "de retorno", "espontánea", "facilitada", "forzosa", "ilegal", "individual", "interna", "internacional", "irregular", "laboral", "masiva", "neta", "ordenada", "regular" y "total” (OIM, 2006, p. 38-41). La mera enumeración de los sentidos del término migración muestra, a un mismo tiempo, lo variado y complejo que es su significado y los múltiples modos en que pudiera resultar elusiva, equívoca, ambigua. De esta manera, en el marco de estos múltiples sentidos que el término migración presenta, se pretende destacar algunos de los aspectos relacionados con el objetivo del trabajo.

En primer lugar, las migraciones constituyen un proceso fuerte y dinámico que ha sido capaz de ir transformando las sociedades en varias de sus características, pasando a ser (como en muchos países) una problemática nacional que requiere de decisiones rápidas y urgentes por parte del Estado y sus instituciones. En concordancia con lo anterior, la ONU plantea que en el año 2013 existían 232 millones de migrantes en el mundo, cifras que con el pasar del tiempo se modifican por distintas razones como las guerras (en el caso de Medio Oriente) o por la búsqueda de nuevos horizontes laborales y/o personales (como es la realidad en América del Sur).

Lo anterior constituye un llamado de atención a las autoridades nacionales e internacionales, pues la migración ya no solo representa el ingreso v/s la 
salida de personas desde algún lugar en particular, sino que, las migraciones son parte de la agenda pública. Aunque, por cierto, no se trata únicamente de una cuestión de cantidad. Por ejemplo, para la Organización de las Naciones Unidas (ONU) las personas en situación de movilidad, migrantes y refugiados, que circulan en zonas fronterizas suelen enfrentar situaciones que pueden significar una amenaza a sus derechos fundamentales.

Es interesante hacer notar en este punto la tensión que existe entre la Declaración Universal de los Derechos Humanos y algunas normativas migratorias o leyes de extranjería de algunos países signatarios de la misma. Según Vide Mazza (2015, p. 252):

A atual fase de regulação do modelo econômico e do projeto político ocidental, do ponto de vista legal, enfrenta impasses no encaminhamento de situaçóes ligadas ao direito humano à mobilidade. Por um lado a DUDH (Declaración Universal de Derechos Humanos), carta maior que agrega diferentes povos e culturas num projeto universalista de direitos humanos com respeito ao relativismo cultural, ao multiculturalismo, a uma cidadania universal; por outro, as Diretivas que restringem a efetivaçáo destes fundamentos e se apoiam em preconceitos xenófobos de segmentos da sociedade civil que solicitam açôes restritivas por parte do Estado.

En otras palabras, pueden convivir en un mismo Estado, paradojalmente, una visión centrada en la igualdad, la libertad y la diversidad con normativas que ponen amplias trabas a la migración o, como en el caso chileno, donde ni siquiera están actualizadas (CHILE, 2005b)5.

Por otro parte, la arbitrariedad y los abusos posibilitan la exposición de los migrantes y de los refugiados a los riesgos de la migración irregular, a las redes de trata de personas y tráfico, y a la violencia sexual y basada en género. En todos estos casos, el elemento común de las circunstancias de las personas, radica en su vulnerabilidad, en su incapacidad para demandar el acceso a bienes y derechos.

Por ello, no debe extrañar que en el año 2013 se elabore el Informe sobre las Migraciones en el Mundo, teniendo como objetivo el contribuir al debate mundial sobre la migración a través de tres medidas concretas, que a continuación se mencionan:

1. Centrar la atención en todas las direcciones del movimiento migratorio: tradicionalmente, la atención se ha centrado en la migración desde los países de ingresos bajos o medianos hacia los más prósperos, pero en el Informe se examinan otras tres direcciones de la migración — entre países de ingresos bajos y medianos o altos, y la migración desde los países ricos, del mundo industrializado, hacia los países relativamente más pobres - así como sus repercusiones en el desarrollo (OIM, 2013, p. 185); 
2. Orientar el centro de interés hacia el bienestar de los migrantes y su calidad de vida, en vez de centrarse en las remesas y las repercusiones de la migración en la vida económica y en el comercio, como se ha hecho en el pasado (OIM, 2013, p. 183);

3. Contribuir al debate sobre el modo de integrar la migración en la Agenda Mundial para el Desarrollo después de 2015. A pesar del creciente interés en la migración y el desarrollo, la cuestión no figuraba en los Objetivos de Desarrollo del Milenio, ni es objeto de incorporación sistemática en los planes nacionales de desarrollo (OIM, 2013, p. 181).

Existe, entonces, la necesidad de subrayar que el carácter de asunto público de la migración no es solo una cuestión de voluntad; se trata, en sentido estricto, de hacer pasar los desafíos de la migración a la agenda pública. Supuesto, además, que integrarlo en dicha agenda, permitirá transformar los desafíos en plan de acción, por ejemplo, en el plano educacional, laboral o sanitario. En parte importante porque a pesar de estas propuestas, "la migración sigue sin estar adecuadamente integrada en los marcos de desarrollo y políticas sectoriales más amplias, tanto en los planos nacional y local como en las agendas mundiales de desarrollo" (OIM, 2013, p. 183). Estas ideas, más los planteamientos hechos con anterioridad, serán discutidos en el siguiente apartado, vale decir, en las consecuencias para la educación en el caso chileno.

\section{Consecuencias para la educación chilena}

Dados los rasgos que presentan los antecedentes respecto de la migración, convendrá recordar, como hacen Bellolio \& Errázuriz (2014), que una parte importante de los migrantes al país provienen de países limítrofes y desarrollan una migración de corto plazo, según lo señalan Joiko y Vaquez (2016) con la expectativa de retornar prontamente a sus países de origen; históricamente, por el contrario, la migración extracontinental representaba un horizonte de vida en el largo plazo (LARA, 2014). El carácter "temporario" de la migración más reciente, plantea una serie de limitaciones a la posibilidad de atender los requerimientos de las personas que se incorporan al país. En particular, plantean interrogantes respecto de la capacidad del sistema educativo para atender las necesidades de niños, niñas y adolescentes (BASSA; TORRES, 2015).

A este respecto, convendrá señalar que en Chile la migración es un fenómeno de larga data histórica, pero que, no obstante, no puede decirse que el país haya presenciado nunca un movimiento masivo de personas. Bellolio \& Errázuriz (2014, p. 15), señalan conforme a la Tabla 1 que el Producto Interno Bruto (PIB) se distribuye del siguiente modo en algunos países de América Latina. 
De acuerdo con la Tabla 1, el de Chile, es el PIB comparativamente más alto. Este considera que, en el año 2014, el Departamento de Extranjería y Migración $(\mathrm{DEM})^{6}$, estimó el total de extranjeros residentes en cerca de 411.000 migrantes permanentes, lo que correspondería al 2,3\% de la población nacional (OIM, 2011), conforme lo muestra la tabla $2^{7}$ :

Los principales asentamientos de migrantes a nivel subnacional, es decir, su distribución territorial regional en el país, se concentran en la Región Metropolitana con el 61,5\%, seguido de la región de Antofagasta con un 6,9\% y las regiones de Tarapacá y Valparaíso con el 6,0\% y 5,8\%, respectivamente (ver Tabla 3). Tomando como referencia el año 2005, el mayor crecimiento del número de migrantes ha tenido lugar en las regiones de Antofagasta, donde se duplica el porcentaje de asentamiento, y la de Tarapacá, con un incremento superior al $60 \%$.

De acuerdo con la identificación de las comunidades migrantes con mayor representación en Chile, estas se concentran fuertemente en personas procedentes de países latinoamericanos (ver Tabla 4), así "la principal comunidad

\section{Tabla 1}

Producto Interno Bruto (PIB) per cápita corregido por paridad de poder de compra (US\$).

\begin{tabular}{c|c}
\hline Países & PIB \\
\hline Argentina & 18.749 \\
\hline Bolivia & 5.364 \\
\hline Chile & 19.067 \\
\hline Colombia & 11.189 \\
\hline Ecuador & 10.080 \\
\hline Perú & 11.124 \\
\hline
\end{tabular}

Fuente: IMF, 2014.

Tabla 2

Estimación de residentes extranjeros en Chile.

\begin{tabular}{l|c|c|c}
\hline Año & $\begin{array}{c}\text { Total de residentes } \\
\text { extranjeros }\end{array}$ & $\begin{array}{c}\text { Porcentaje respecto a } \\
\text { población total }\end{array}$ & Referencia \\
\hline 1982 & 83.805 & $0,7 \%$ & Censo \\
\hline 1992 & 105.070 & $0,8 \%$ & Censo \\
\hline 2002 & 195.320 & $1,2 \%$ & Censo \\
\hline 2005 & 212.935 & $1,3 \%$ & Estimación \\
\hline 2010 & 305.212 & $1,8 \%$ & Estimación \\
\hline 2014 & 410.998 & $2,3 \%$ & Estimación \\
\hline
\end{tabular}

Fuente: Rojas y Silva (2016). 
Tabla 3

Asentamiento de residentes extranjeros por región en Chile.

\begin{tabular}{l|c|c|c|c|c|c}
\hline \multirow{2}{*}{ Regiones } & \multicolumn{3}{|c|}{ Asentamiento (\%) } & \multicolumn{3}{c}{$\begin{array}{c}\text { Participación respecto } \\
\text { a población regional }\end{array}$} \\
\cline { 2 - 7 } & $\mathbf{2 0 0 5}$ & $\mathbf{2 0 1 0}$ & $\mathbf{2 0 1 4}$ & $\mathbf{2 0 0 5}$ & $\mathbf{2 0 1 0}$ & $\mathbf{2 0 1 4}$ \\
\hline Arica & 3,1 & 3,3 & 3,3 & 3,2 & 4,6 & 5,8 \\
\hline Tarapacá & 3,6 & 5,2 & 6,0 & 2,9 & 5,3 & 7,4 \\
\hline Antofagasta & 3,1 & 4,4 & 6,9 & 1,2 & 2,3 & 4,6 \\
\hline Atacama & 0,6 & 0,7 & 1,0 & 0,5 & 0,8 & 1,3 \\
\hline Coquimbo & 1,6 & 1,5 & 1,6 & 0,5 & 0,7 & 0,9 \\
\hline Valparaíso & 7,9 & 6,6 & 5,8 & 1,0 & 1,2 & 1,3 \\
\hline Metropolitana & 59,0 & 61,7 & 61,5 & 1,9 & 2,7 & 3,5 \\
\hline O'Higgins & 1,5 & 1,4 & 1,3 & 0,4 & 0,5 & 0,6 \\
\hline Maule & 1,6 & 1,3 & 1,2 & 0,4 & 0,4 & 0,5 \\
\hline Biobío & 3,6 & 3,1 & 2,7 & 0,4 & 0,5 & 0,5 \\
\hline Araucanía & 3,6 & 2,8 & 2,2 & 0,8 & 0,9 & 0,9 \\
\hline Los Ríos & 1,2 & 0,9 & 0,8 & 0,7 & 07 & 0,8 \\
\hline Los Lagos & 2,8 & 2,3 & 1,9 & 0,8 & 0,9 & 0,9 \\
\hline Aysén & 0,7 & 0,5 & 0,4 & 1,5 & 1,5 & 1,7 \\
\hline Magallanes & 0,9 & 0,8 & 0,7 & 1,3 & 1,5 & 1,8 \\
\hline
\end{tabular}

Fuente: Rojas y Silva (2016).

Tabla 4

Porcentaje de población migrante en comunidades principales.

\begin{tabular}{l|c|c|c}
\hline \multirow{2}{*}{ País } & \multicolumn{3}{|c}{ Participación respecto a población regional } \\
\cline { 2 - 4 } & $\mathbf{2 0 0 5}$ & $\mathbf{2 0 1 0}$ & $\mathbf{2 0 1 4}$ \\
\hline Perú & 20,6 & 30,4 & 31,7 \\
\hline Argentina & 25,2 & 19,9 & 16,3 \\
\hline Bolivia & 5,9 & 6,4 & 8,8 \\
\hline Colombia & 2,4 & 3,6 & 6,1 \\
\hline Ecuador & 5,1 & 5,0 & 4,7 \\
\hline Espańa & 4,7 & 3,7 & 3,5 \\
\hline Estados Unidos & 4,5 & 3,6 & 3,1 \\
\hline Brasil & 3,8 & 3,2 & 3,0 \\
\hline Venezuela & 2,2 & 1,9 & 1,9 \\
\hline China & 1,1 & 1,6 & 1,9 \\
\hline Otros Países & 24,5 & 20,7 & 19,1 \\
\hline
\end{tabular}

Fuente: Rojas y Silva (2016). 
residente es la de los peruanos $(31,7 \%)$, seguidos por argentinos (16,3\%), bolivianos $(8,8 \%)$, colombianos $(6,1 \%)$ y ecuatorianos $(4,7 \%)$ " (ROJAS; SILVA, 2016, p. 14).

De hecho, lo que muestra la Tabla 4 constituye uno de los rasgos salientes de la situación migratoria en Chile. Se trata de grupos que proceden de países limítrofes, es el caso de Perú, Argentina y Bolivia, excepción hecha de Colombia y Ecuador, siendo del primero de estos dos países del que procede la migración más notoria, especialmente en la región de Antofagasta en los últimos años. A nivel de migración total por género, esta presenta un alto grado de feminización para Chile. En efecto, de acuerdo con la información del Departamento de Extranjería y Migración (ROJAS; SILVA, 2016, p. 19) en el año 2005 un 51,6\% de los migrantes correspondía a mujeres, durante el año 2010 este porcentaje se incrementó hasta un 52,2\%, mientras que durante el año 2014 la migración femenina constituye un 52,6\%.

Las tendencias etarias de los extranjeros en el país, por otra parte, dan cuenta de una fuerte concentración en grupos jóvenes y de adultos jóvenes que, por cierto, constituye parte del grupo objetivo de mayor interés para el sistema educativo, por la razón obvia que se relaciona con la necesidad de prestar atención a sus necesidades de aprendizajes. La Tabla 5 nos indica en este sentido:

Para el caso de la contextualización del fenómeno migratorio en las escuelas, como lo señalan Fernández (2012) y Joiko \& Vasquez (2016), no existe información precisa. Pese a ello, el Ministerio de Educación para marzo de 2016 indica que de un total de 3.550.837 estudiantes matriculados en el sistema escolar, 61.085 corresponde a extranjeros, es decir, un 1,7\% de la población total. De ellos 33.613 se halla matriculado en establecimientos municipales; 20.387, en particulares subvencionados; 6.160, en particulares pagados y 925 en corporaciones de administración delegada. En cuanto al país de origen con mayor presencia en orden decreciente son Perú (5.289), Colombia (4.053), Bolivia (3.974), Haití (916), Venezuela (711) y Ecuador (664).

\section{Tabla 5}

Porcentaje de población migrante por tramo etario.

\begin{tabular}{l|c|c|c}
\hline \multirow{2}{*}{ Tramo } & \multicolumn{3}{|c}{ Participación respecto a población total } \\
\cline { 2 - 4 } & $\mathbf{2 0 0 5}$ & $\mathbf{2 0 1 0}$ & $\mathbf{2 0 1 4}$ \\
\hline 0 a 19 años & 26,2 & 23,7 & 21,6 \\
\hline 20 a 35 años & 36,5 & 40,7 & 43,3 \\
\hline 36 a 50 años & 19,5 & 20,8 & 22,2 \\
\hline 51 a 65 años & 9,3 & 8,5 & 8,0 \\
\hline 66 ańos o más & 8,5 & 6,3 & 4,8 \\
\hline
\end{tabular}

Fuente: Rojas y Silva (2016). 
Pese a que el porcentaje de $1,7 \%$ señalado es cuantitativamente menor, el Estado chileno, según lo estipula la Ley General de Educación (LGE) (Ley no 20.370, del 12 de septiembre de 2009), debe garantizar el derecho a educación a todas las personas que se encuentren en el territorio del país, sin discriminación (Art. 19 no 10 de la Constitución Política de la República y Art. 50 de la Ley General de Educación no 20.370) (CHILE, 2009).

En la actualidad, las principales normativas legales vigentes para los migrantes en el sector educativo se establecen en la ordenanza no 07/1008 de 2005, el cual fija instrucciones asociadas al ingreso, permanencia y ejercicio de los derechos de los estudiantes migrantes en los establecimientos educacionales que cuentan con reconocimiento oficial, acorde con las políticas sobre migración vigentes (CHILE, 2005a).

Solo recientemente, durante el ańo 2015, se elabora y distribuye el Instructivo Presidencial $n^{\circ}$ 05, en el que se dispone que respecto a la población migrante la actuación del Estado deberá aplicar los estándares de derechos humanos consagrados en los instrumento internacionales ratificados por Chile y, específicamente, en la tercera instrucción, se mandata al Ministerio de Educación "a velar para que se garantice a niños, niñas y adolescentes de familias migrantes, el acceso, permanencia y progreso de su trayectoria educativa, en igualdad de condiciones, con independencia de su nacionalidad, origen o situación migratoria" (CHILE, 2015, p. 7).

Este planteamiento es refrendado por la actualización de instrucciones por parte de la Subsecretaría de Educación, dependiente del Ministerio de Educación de Chile (CHILE, 2016). En especial, los procedimientos actualizados dan cuenta de los procesos que deben velarse: matrícula, su certificación y acciones vinculadas que faciliten la inclusión escolar. Estableciéndose como elementos esenciales que, en cuanto a la incorporación, y a contar de enero de 2017, a todo migrante que no cuente con Cédula de Identidad Chilena y quiera incorporarse al sistema escolar, se le asignará, a través de las Oficinas de Atención Ciudadana de Ayuda del Ministerio de Educación, un "identificador provisorio escolar" (IPE), número único, que el estudiante deberá mantener hasta que tenga regularizada su situación migratoria, permitiendo efectuar los registros académicos en actas y los procesos de certificación asociados.

Asimismo, en relación con la matrícula provisoria, ésta se otorgará para el curso al que ingresa el niño, niña o adolescente, considerando la documentación escolar o la edad, mientras se realiza el Reconocimiento de Estudios o Proceso de Validación, que permita certificar el último curso aprobado. Una vez realizado lo anterior, la matrícula será definitiva, aun cuando el alumno no cuente todavía con Cédula de Identidad para chilenos o para extranjeros.

Por otra parte, todos los niños, niñas y adolescentes migrantes matriculados en establecimientos educacionales chilenos, al ser estudiantes regulares, 
tienen los mismos derechos que los nacionales respecto de la alimentación escolar, textos escolares, pase escolar y seguro escolar. Los estudiantes migrantes y sus padres o tutores, tienen igual derecho a participar de las organizaciones de Centros de Padres, Centros de Alumnos, Consejo Escolar u otras existentes en los establecimientos educacionales. Finalmente, de ser necesario, los establecimientos educacionales establecerán procedimientos adecuados en sus respectivos Reglamentos Internos de Evaluación, para que los niños, niñas y adolescentes migrantes puedan incorporarse paulatinamente a los procesos de evaluación, especialmente en el caso que no tengan dominio del idioma espańol.

Nótese que dicha Ordenanza regula u operacionaliza, más bien, una serie de acciones básicas del funcionamiento escolar en relación con los migrantes, de forma que pone en evidencia la precariedad estructural de los protocolos de actuación escolar chilena respecto del acceso, la retención, la participación familiar y, en fin, de la certificación de los estudiantes de origen extranjero, que pertenecen a algunos de los grupos de migrantes antes descritos, haciendo evidente la falta de políticas públicas al respecto. Baste con mencionar que la Ley de Extranjería, que regula el tema migratorio en Chile, es del año 1975, esto es, corresponde a los inicios de la dictadura cívico-militar ${ }^{8}$.

Como puede preverse a partir de las características de los modelos educativos de Francia y EE.UU. a los que se aludió antes para aproximarse a la cuestión de la relación de los grupos de migrantes con las comunidades de destino, la estructura de un sistema educativo chileno, en cuanto esta se expresa en una cierta institucionalidad, pone de manifiesto también la concepción general en que descansa la educación de un país. Es decir, en la estructura institucional se encuentra presentes ya los principios y criterios que orientan la función del sistema y que, en el caso chileno, son casi ausentes.

Lo anterior constituye un llamado de atención a las autoridades nacionales e internacionales, pues la migración ya no solo representa el ingreso v/s la salida de personas desde algún lugar en particular, sino que, las migraciones son parte de la agenda pública. Aunque, por cierto, no se trata únicamente de una cuestión de cantidad.

Existe, entonces, la necesidad de subrayar que el carácter de asunto público de la migración no es solo - aunque por cierto que lo es también una cuestión de voluntad; se trata, en sentido estricto, de hacer pasar los desafíos de la migración a la agenda pública. Supuesto, además, que integrarlo en dicha agenda, permitirá transformar los desafíos en plan de acción. En parte importante porque a pesar de estas propuestas, "la migración sigue sin estar adecuadamente integrada en los marcos de desarrollo y políticas sectoriales más amplias, tanto en los planos nacional y local como en las agendas mundiales de desarrollo" (OIM, 2013, p. 183). 


\section{Notas}

1. Ferrater Mora (1964) consigna 255 entradas que identifican sendas referencias al concepto "moderno". Ello sin considerar las múltiples variaciones del mismo.

2. Melting Pot apareció como uno de los tres modelos de integración en Estados Unidos, diferente de la anglo-conformity (asimilación de la cultura anglosajona mayoritaria) y del pluralismo. La fusión cultural era considerada otro de los modelos con los que se ha abordado la problemática de la integración social en sociedades intensamente diversificadas en lo relativo a culturas, razas, lenguas y religiones (MALGENESINI; GIMÉNEZ, 1997).

3. El título en inglés es $A$ letter concerning Toleration, being a Translation of Epistola de Tolerancia y es posible encontrarlo en la versión en inglés The Works of John Locke, a New Edition, Corrected, in ten volumes, v. VI, London, 1823 (Nachdruck Scientia Verlag AALEN, Germany, 1963). Locke publicó, como se dijo, en el año 1689 la Carta sobre la tolerancia, la que tiene tres versiones más: la Segunda Carta sobre la tolerancia, la Tercera Carta sobre la tolerancia y la Cuarta Carta sobre la tolerancia.

4. Hay múltiples maneras de entender el concepto de "multiculturalidad", en este caso, lo comprendemos como sinónimo de "entrelazamiento de lo propio y de lo ajeno" (Verflechtung von Eigenem und Fremdem) según B. Waldenfels, es decir, como una interrelación donde exista un grado cambiante entre cercanía y lejanía entre las culturas. Este criterio es muy interesante, porque busca romper la aparente rigidez de conceptos como "propio" y "ajeno" y busca plantear que nosotros vivimos en la cultura de los otros, como los otros viven en nuestra cultura. "Nosotros encontramos lo ajeno no primero afuera, sino que dentro, en la propia casa, en nuestro propio país y en nuestra propia cultura, con cambiantes grados de ajenidad" (WALDENFELS, 2015, p. 15, traducción nuestra).

5. No podemos desarrollar más este punto, sin embargo, remitimos al lector al interesante artículo de Débora Mazza (2015) citado en la bibliografía.

6. El Departamento de Extranjería y Migración (DEM) es un organismo dependiente del Ministerio de Interior y Seguridad Pública del Gobierno de Chile, al cual le corresponde recibir las solicitudes de permisos de residencia provisionales o definitivas de aquellos migrantes ya ingresados al país y aprobar (o no) su otorgamiento. Junto al Ministerio de Relaciones Exteriores y la Policía de Investigaciones de Chile, constituyen las tres instituciones vinculadas al control fronterizo.

7. La estimación del Departamento de Extranjería y Migración (DEM) toma como base los extranjeros contabilizados en el último Censo válido (2002), agregándose los permisos de permanencia definitiva de los extranjeros que no fueron contabilizados en el Censo (INSTITUTO NACIONAL DE ESTADÍSTICAS, 2003).

8. No es fácil establecer una hipótesis explicativa acerca de por qué los gobiernos democráticos posteriores a la dictadura cívico-militar no enviaron al Congreso Nacional una nueva propuesta de ley. Una explicación plausible es la falta de voluntad política. Hasta el momento, el fenómeno de la migración en Chile es regido por el Decreto Ley no 1.094, conocido como "Ley de extranjería”, que fue publicado en el Diario Oficial el 19 de julio de 1975. A ello se suma, entre otros, el Decreto Supremo no 597 de 1984, conocido como el "Reglamento de Extranjería” y el Decreto 
Supremo no 5.142 de 1960, referido a la "nacionalización de extranjeros". Es decir, normas legales que fueron promulgadas durante la dictadura militar o hace más de 50 años, en un contexto cultural muy diferente al actual. La no existencia, entonces, de una ley de extranjería y migración actualizada y acorde a los desafíos que vive el país, deja a los migrantes expuestos a la voluntad y el arbitrio de las personas y de las instituciones. Ciertamente, en algunos casos, instituciones como el Ministerio de educación o el Ministerio de Salud han respondido positivamente garantizando a los migrantes el acceso a sus servicios, con independencia, incluso, de si el migrante ha regularizado o no su situación. Lo anterior se sustenta en los diversos convenios internacionales que el Estado de Chile ha suscrito en materia de derechos humanos. Sin embargo, por todos es conocido los abusos que son víctima los migrantes en temas laborales o de vivienda. Muchos migrantes trabajan en Chile sin contrato o pagan cifras desproporcionadas por un arriendo. Por estas razones urge la necesidad de un cuerpo legal que establezca los deberes y derechos que deben tener en nuestro país las personas que quieran asentarse en él. Este cuerpo legal debiera hacer que la migración cumpla con los principios que la Organización Internacional para las migraciones (OIM), dependiente de Naciones Unidas, ha establecido para ella: la migración deber ser regular, ordenada y segura. Por lo anterior, si bien hay que destacar la iniciativa que tuvo el gobierno del Presidente Sebastián Piñera, que envió un proyecto de ley sobre migración y el anuncio que hizo la Presidenta Michelle Bachelet, en su discurso ante el Congreso Nacional, el pasado 01 de junio, llama la atención la demora que ha tenido el ejecutivo para enviar el mencionado proyecto a trámite, cuestión que recién se hizo el 21 de agosto de 2017. Recientemente, el lunes 23 de abril de 2018, el segundo gobierno del presidente Sebastián Pińera ha iniciado un proceso de regularización de migrantes que hayan entrado ilegalmente al país. Lo que llama la atención, es por qué no realizó este proceso el gobierno de Michelle Bachelet, de centro izquierda, más proclive a la migración que el segundo gobierno de centro derecha de Piñera.

\section{Referencias}

ATRIA, F. Derechos sociales y educación: un nuevo paradigma de lo público. Santiago do Chile: LOM, 2014.

BASSA, J.; TORRES, F. Desafíos para el Ordenamiento Jurídico Chileno ante el Crecimiento Sostenido de los Flujos Migratorios. Estudios Constitucionales, v. 13, n. 2, p. 103-124, 2015. https://dx.doi.org/10.4067/S0718-52002015000200004

BELlOLIO, A.; ERRÁZURIZ, H. Migración en Chile: oportunidad ignorada. Santiago: Libertad y Desarrollo, 2014.

CHILE. Ministerio de Educación. Ley General de Educación, no 20.370/2009. 2009. Disponible en: <http://portales.mineduc.cl/usuarios/convivencia escolar/ doc/201103050142570.Ley N 20370 Ley General de Educacion.pdf>. Acceso en: 7 dic. 2017.

Ministerio de Educación. Ord. no $07 / 1008$ (1531), del 04 de agosto de 2005. Instruye sobre el ingreso, permanencia y ejercicio de los derechos de los alumnos(as) inmigrantes en los establecimientos educacionales que cuentan con reconocimiento oficial. Chile, 2005a. 
. Ministerio Secretaría General de Gobierno. Constitución Política de la República de Chile. Decreto supremo no 100 de septiembre 22 de 2005. Fija texto refundido, coordinado y sistematizado de la Constitución Política de la República de Chile. 2005b.

Presidencia República de Chile. Instructivo Presidencial no 5. Fija Lineamientos e Instrucciones para la Política Nacional Migratoria, 06 de noviembre de 2015. Chile, 2015.

Subsecretaría de Educación de Chile. Ord. no 02/000894 del 07 de noviembre de 2016. Actualiza instrucciones sobre el Ingreso, permanencia y ejercicio de los derechos de estudiantes migrantes en los establecimientos educacionales que cuentan con reconocimiento oficial. 2016.

FERNÁNDEZ, R. Una mirada a los derechos de los niños, niñas y adolescentes inmigrantes en Chile. Avances y desafíos pendientes. In: ALTO COMISSARIADO DAS NAÇÓEES UNIDAS PARA OS REFUGIADOS (ACNUR); ORGANIZACIÓN INTERNACIONAL PARA LAS MIGRACIONES (OIM); FUNDO DAS NAÇÓES UNIDAS PARA A INFÂNCIA (UNICEF). Los derechos de los niños, niñas y adolescentes migrantes, refugiados y víctimas de trata internacional en Chile: avances y desafíos. Santiago de Chile: Andros Impresores, 2012. Disponible en: shttp://unicef.cl/web/los-derechos-delos-ninos-ninas-y-adolescentes-migrantes-refugiados-y-victimas-de-trata-internacionalen-chile-avances-y-desafios/>. Acceso en: 24 nov. 2016.

FERRATER MORA, J. Diccionario de Filosofía. México: FCE, 1964.

GARCÍA-CANCLINI, N. Consumidores y ciudadanos: conflictos multiculturales de la globalización. México: Grijalbo, 1995.

HABERMAS, J. El discurso filosófico de la modernidad. Madrid: Taurus, 1993.

INSTITUTO NACIONAL DE ESTADÍSTICAS. Censo 2002. Santiago de Chile: Gobierno de Chile, 2003.

INTERNATIONAL MONETARY FUND (IMF). World Economic Outlook Database, World Economic and Financial Surveys. Washington, D.C.: IMF, 2014.

JOIKO, S.; VASQUEZ, A. Acceso y elección escolar de familias migrantes en Chile: "No tuve problemas porque la escuela es abierta, porque acepta muchas nacionalidades". Calidad en la Educación, n. 45, p. 132-173, 2016. http://dx.doi.org/10.4067/S0718$\underline{45652016000200005}$

LARA, M. Evolución de la legislación migratoria en Chile claves para una lectura (18242013). Revista de Historia del Derecho, n. 47, p. 59-104, 2014. Disponible en: <http:// www.scielo.org.ar/scielo.php?script=sci arttext\&pid=S1853-17842014000100004\&lng =es\&tlng=es $>$. Acceso en: 24 nov. 2016.

LOCKE, J. Carta sobre la tolerancia. Madrid: Tecnos, 1994.

MALGENESINI, G.; GIMÉNEZ, C. Guía de conceptos sobre migraciones, racismo e interculturalidad. Madrid: La Cueva del Oso, 1997.

MAZZA, D. O direito humano a mobilidades: dois textos e dois contextos. Revista Interdisciplinar de Mobilidade Humana, Brasília, v. 23, n. 44, p. 237-257, 2015. 
ORGANIZACIÓN INTERNACIONAL PARA LAS MIGRACIONES (OIM). Glosario sobre migraciones. 2006. Disponible en: shttp://publications.iom.int/system/files/pdf/ iml 7 sp.pdf $>$. Acceso en: 24 mar. 2017.

Informe sobre las migraciones en el mundo. Ginebra: OIM, 2013.

. Perfil Migratorio de Chile. Buenos Aires, Argentina, 2011. Disponible en: $\leq$ http:// priem.cl/wp-content/uploads/2015/04/Stefoni Perfil-Migratorio-de-Chile.pdf $>$. Acceso en: 23 nov. 2016.

ROJAS, N.; SILVA, C. La migración en Chile: breve reporte y caracterización. Informe Observatorio Iberoamericano sobre Movilidad Humana, Migraciones y Desarrollo OBIMID. 2016. Disponible en: shttp://www.extranjeria.gob.cl/media/2016/08/ informe julio agosto 2016.pdf $>$. Acceso en: 14nov. 2016.

WALDENFELS, B. Fremdheit innerhalb und außerhalb unserer eigenen Kultur. In: GUTJAHR, O. (Org.). Interkulturalität. Konstruktionen des Anderen. Würzburg: Könighausen \& Neumann, 2015. p. 211-231.

WALZER, M. Tratado sobre la tolerancia. Barcelona: Paidós, 1998.

WEBER, M. La ética protestante y el espíritu del capitalismo. Puebla: Premia, 1991.

Recebido em 17 de abril de 2017.

Aceito em 08 de abril de 2018. 